\title{
Perceived Use of Metacognitive Strategies by EFL Undergraduates in Academic Reading
}

\author{
Kasyfur Rahman
}

Universitas Islam Negeri Mataram, Indonesia

Correspondence: Kasyfur Rahman, Universitas Islam Negeri Mataram; Indonesia. e-mail kasyfurrahman@uinmataram.ac.id

Submitted: March 08, 2020

DOI: 10.29408/veles.v4i1.1975

Revised: April 06, $2020 \quad$ Accepted: April 09, 2020

URL: http://dx.doi.org/10.29408/veles.v4i1.1975

\begin{abstract}
While investigations on metacognitive awareness in reading comprehension have yielded inconsistent results despite similar instruments, there is a need to expand the previous studies particularly into Indonesian tertiary EFL context in order to validate the findings. This paper seeks to quantitatively explore perceived use of metacognitive strategies in reading academic texts through an online questionnaire administered to 66 final year EFL undergraduates in an Indonesian university. Generally, the findings suggest moderate to high use of metacognitive strategies. More specifically, the findings demonstrate a high frequency of problem-solving strategies in comparison with the global and support strategies. Least moderate perceived use of several strategies is likely to be influenced by the students' limited academic reading experience and limited reading schemata. Therefore, this research confirms the previous research that demonstrates problem-solving strategies as mostly perceived strategies by English nonnative students in their reading. The findings also advocate the need for the teaching of several strategies that demonstrate moderate frequencies yet highly needed for academic reading purposes.
\end{abstract}

Keywords: Metacognitive strategies, academic reading

\section{Introduction}

Reading academic texts has been nowadays sine qua non for students of higher education no matter at which degree they are studying. The advent of information technology meanwhile speeds up and multiplies the accessibility of academic texts, paid or open access, therefore provides spaces of myriad of accessible texts. Nonetheless, this kind of reading is painstaking as even proficient readers still find it daunting to extract important information from academic text. In the case of EFL undergraduates, the acquaintance with academic texts: book chapters, journal articles, conference paper, and thesis starts in the early phase of higher education. As reported by Hermida (2009), most early year university students use the way they read during secondary 
school when required to read in the context of higher education. This bizarre phenomenon might bring about low-quality reading since reading academic text requires higher order thinking skills, and it is intended to synthesize and construct arguments. Hamilton (2018), similarly, justifies that undergraduates are novice academic readers. Hermida (2009) argues that undergraduates mostly use surface approach to text reading. Meanwhile, in the context EFL, the foreign language upscales the complexity of the text which leads to confusion about the ideas and arguments posed by the authors of the scientific works.

Success in academic reading comprehension is multifactorial; it is influenced by at least three factors: reader characteristics, the properties of the texts, and the demand of the reading task bound within sociocultural context (Snow, 2010). Perhaps the most sophisticated factor is reader characteristics as it entails plethora of elements such as motivation, strategies, preferences, learning styles, vocabulary mastery, and even familiarity with the topics. Among these elements, reading strategies have been widely investigated in the last few decades. Learner strategies are any efforts made by learners in order to accomplish a task for enhanced learning. Chamot and O'Malley (1994) categorizes learners' strategy into a taxonomy of metacognitive, cognitive, and social/affective strategies. Cognitive strategies are direct interaction with a task and incoming information that enable learners to manipulate them to improve learning. This can be carried out through several activities: predicting from context, summarizing, looking up words in dictionary, skipping problematic parts, activating prior knowledge, note-taking, and making use of topics, linguistic clues as well as textual markers, and repetition of words or phrases (Ahmadi, Ismail \& Abdullah, 2013). On the other hand, metacognitive strategies refer to regulating and monitoring these cognitive processes. In line with this, Di Martino and La Marca (2019) point out that metacognition entails two elements: knowledge and regulation. The first involves the knowledge on the strategies and when as well as why use them while the latter refers to monitoring the cognition which may be in the forms of planning, awareness, and evaluation of the reading processes.

Research on metacognitive awareness on reading comprehension has been one of the major interests to language and language education researchers. Miller (2017) for instance, reports on a small-scale research project on the metacognitive awareness and reading strategies of ESL students that problem-solving strategies are among the mostly used strategies with support and global strategies following respectively. Similar study by Yuksel and Yuksel (2012), whose research was on Turkish academic reading strategies, yielded identical results. In contrast, a study by Dumlaio, Himmapan, Kueasnou, and Wanakprakobkul (2019) investigating the metacognitive awareness of reading strategy and students' perceived use of them reports that the students used global reading strategies more frequently than problem solving ones. Quite divergently, a study by Al-Mekhlafi (2017) demonstrates that despite various levels of English proficiency, there was no significant differences of the use of the three types of reading strategies and the findings also suggest similarly high use of those strategies. This study employed MARSI (Metacognitive Awareness Reading Strategy Inventory) developed by Mokhtari and Reichard (2002) as the research instrument. Another research study by Hassan 
(2018) whose research investigates the relationship between metacognitive strategy awareness and L1 and L2 reading ability. She revealed that metacognitive strategy awareness notably promotes L1 and L2 reading ability. Similar study by Sheikh, Soomro, and Hussain (2019) also unveiled that awareness on metacognitive strategies in reading considerably predict academic achievement as well as suggest the need for workshop or training on MARSI promotion. In contrast, Dardjito (2019) found out, by administering a questionnaire and academic reading test on reading strategies on 373 participants, that there was no significant correlation between metacognitive awareness in reading strategies and their academic reading attainment. These inconsistent results are likely to be resulted from the respondents' perception as Mokhtari (2017) arguably states that the measures of metacognitive awareness they developed do not address the real use of the strategies but the perceived use of the strategies instead. Therefore, both MARSI (Mokthari and Reichard, 2002) and SORS (Mokhtari and Sheorey, 2002) standing for Survey of Reading Strategies, should be used in caution and the results may vary according to the students' perception and their understanding on the questions or statements in the measure instrument. In this research I aim to explore metacognitive strategies use as perceived by EFL undergraduates when coming across academic texts such as textbook or journal articles.

\section{Method}

\subsection{Participants}

The respondents in this research were 66 tertiary EFL students in Universitas Islam Negeri Mataram. Convenience sampling technique was used to determine the respondents as the selection is on the basis of their willingness to participate in the study. These students are also in the final year of their study, therefore the need for academic reading particularly in preparation for thesis composition is imperative.

\subsection{Data Collection}

The data were garnered through a questionnaire based on Mokhtari and Sheorey's (2002) Survey of Reading Strategies (SORS) administered to 66 respondents. The questionnaire consists of thirty items comprising global, problem-solving, and supplementary strategies for reading comprehension which were designed based on MARSI (Metacognitive Awareness of Reading Strategies Inventory) developed by Mokhtari and Reichard (2002). The questionnaire was administered online through google forms using anonymous respondents. The options in the questionnaire is based on Likert scale ( $5=$ Always, $4=$ Usually, $3=$ Sometimes, $2=$ Seldom, $1=$ Never).

\subsection{Data Analysis}

The data collected were quantitatively analyzed in descriptive statistics and linked to current theories and previous research on metacognitive strategies of reading. Furthermore, the data interpretation is based on Mokhtari and Reichard's (2002) order of high ( $M=3.5-5)$, medium (M=2.50-3.49) and low (M=1-2.49) use of the strategies. 


\section{Results}

This section illuminates findings on the survey administered to the respondents to see the tendencies of the metacognitive strategies and sub strategies. Table 1 demonstrates that among the three metacognitive strategies perceived by the students, problem-solving strategies become the most frequently used strategies and supports as well as global strategies following respectively.

Table 1. Overall trend of perceived use metacognitive strategies

\begin{tabular}{lcc}
\hline \multicolumn{1}{c}{ Metacognitive Strategies } & Mean & Rank \\
\hline Global Strategies & 3.51 & 3 \\
Problem-Solving Strategies & 3.85 & 1 \\
Support Strategies & 3.63 & 2 \\
\hline
\end{tabular}

In terms of global strategies, most of the sub strategies as seen in "Table 2" fall within high use $(M=3.5-5)$. The students reported $\mathrm{G} 1$ and $\mathrm{G} 2$ as the most frequently used sub strategies, while the least used strategies are G5, G7, and G10. These least used strategies along with $\mathrm{G} 3$ and $\mathrm{G} 4$ fall within moderate use $(\mathrm{M}=2.50$ - 3.49).

Table 2. Students' report on global reading strategies

\begin{tabular}{llc}
\hline Global Strategies & Mean \\
\hline G1 & Having purposes when reading & 3.91 \\
G2 & Thinking about prior knowledge pertinent to the text for better understanding & 4.06 \\
G3 & Taking overall overview of text before reading & 3.23 \\
G4 & Thinking about the suitability of the text with the reading purpose & 3.41 \\
G5 & Reviewing text through its characteristics such as length and organization & 3.08 \\
G6 & Deciding what to read closely and what to ignore when reading & 3.53 \\
G7 & Using graphic organizers (figures, tables and pictures) to improve & 3.12 \\
& understanding & 3.58 \\
G8 & Using contextual clues for better comprehension & 3.53 \\
G9 & Identifying main information using typographical features (bold or italics) & 3.18 \\
G10 & Critically analyzing and evaluating information in the text & 3.71 \\
G11 & Checking understanding when encountering novel information & 3.73 \\
G12 & Guessing the content of the text when reading & 3.61 \\
G13 & Checking whether the guess made about the text content is right or wrong &
\end{tabular}

Similar to the finding on global reading strategies, most of the sub strategies fall within high use category (see "Table 3"). However, only two (P5 and P6) out of eight sub strategies demonstrate moderate use. This finding shows the predominant use of problem-solving strategies in comparison with the global and support strategies.

Table 3. Students' report on problem-solving strategies 


\begin{tabular}{llc}
\hline Problem-solving Strategies & Mean \\
\hline P1 & Reading slowly and carefully to ensure understanding & 4.23 \\
P2 & Trying to get back on track when losing concentration & 3.98 \\
P3 & Adjusting reading speed in accordance to what is being read & 3.62 \\
P4 & Paying closer attention when text is getting difficult & 4.05 \\
P5 & Pausing time to time and thinking about what is read & 3.30 \\
P6 & Trying visualizing information to memorize what is read & 3.48 \\
P7 & Re-reading text when it becomes difficult to increase understanding & 4.27 \\
P8 & Guessing the meaning of unfamiliar words when reading & 3.89 \\
\hline
\end{tabular}

Table 4 demonstrates that three (S2, S6, and S7) out of nine sub strategies are within moderate use category, while the rest falls within high use category.

Table 4. Students' report on support strategies

\begin{tabular}{llc}
\hline Support Strategies & Mean \\
\hline S1 & Taking notes while reading to help understanding & 3.73 \\
S2 & Reading aloud when text gets difficult to help comprehension & 3.47 \\
S3 & Marking information with underline or circle to remember what is read & 3.98 \\
S4 & Making use of reference material (dictionary, etc.) to help understanding & 3.85 \\
S5 & Paraphrasing for better understanding text & 3.55 \\
S6 & Going back and forth the text to figure out the relationship among ideas & 3.48 \\
S7 & Asking preferred questions to get answered in the text & 3.24 \\
S8 & Translating from English to native language & 3.59 \\
S9 & Thinking about information both in English and native language & 3.76 \\
\hline
\end{tabular}

\section{Discussion}

In this section, the interface between current research findings and previous findings as well as the pertinent theories are discussed. The discussion starts with the summary data of students' preferences of metacognitive strategies they report to see the general trends and mostly used strategies.

By and large, the finding as seen in Table 1 confirms Miller (2017) and if interpreted on the basis of Mokhtari and Reichard's (2002) standards, all of the three sub strategies fall into the category of high use. High use of these strategies generally demonstrates the quality of skilled readers who employ an array of strategies to regulate and monitor their readings.

\subsection{Global Strategies}

Global reading strategies refer to intentionally planned strategies employed by the readers to monitor and manage their reading. Based on the data, most respondents opt for 'sometimes' in terms of global reading strategies which imply moderate use of this sort of strategies on the perceived use of metacognitive awareness in reading comprehension. These findings thus are in line with previous findings by Miller (2017) in which global reading strategies are not the mostly 
perceived use of metacognitive strategies when reading academic texts. As seen in the table, students' reports on the perceived use of global strategies show moderate and high use of these strategies. Item G1 and G2 are on top of the chart showing that their academic reading is perceived as highly purposive and almost always linked to their prior knowledge on the topic. Harrison (2004) classifies reading purposes into three broad categories including reading for enjoyment, a quest for information for research and engagement in contemplation for life. Since these participants are the final year undergraduate students who are demanded to access and process information in academic texts such as journal articles and references book, their main purposes when reading is likely to be the quest for relevant information for their incoming thesis composition. Furthermore, problems in academic reading can be attributed to lacking sufficient vocabulary inventory, limited memory span, failure in understanding the main points and lacking prior knowledge in relation to text topics (Chen, 2017). Nonetheless, the students' responses demonstrate the highest use in terms of thinking about prior knowledge linked to the topics (G2). This strategy also reflects content schemata necessary for reading comprehension. In other words, this finding confirms that these students are highly likely to be able to tackle these insufficiencies. Kendeu \& Den-Broek (2007) revealed that when reading, a reader's working memory is affected by prior knowledge on the text. Thinking about prior knowledge on the topics, therefore helps accelerate cognitive processes necessary to construct and evaluate meaning imperative for academic reading and writing. In contrary, several strategies such as G5, G7, and G10 show the least moderate perceived use. For example, G5, reviewing text through its length and organization contributes the lowest use. Hedgcock and Ferris (2009) suggest the knowledge of formal schemata or macrostructure of the text is vastly facilitative to readers. However, inadequacy of the awareness of text formal schemata might be attributed to limited reading experience especially in a foreign language. Repeated exposure on text structure would likely to help readers build formal schemata. In addition, the case of G7, the use of graphic organizers in reading to help understanding depends largely on the type of text as different texts might have different variety of graphic uses. Finally, G10, critically analyzing and evaluating text is highly important in academic reading, yet demonstrates least moderate perceived use. Most of these strategies are truly essential for academic reading. Cogmen and Saracaloglu (2009) state that students in many classes are scantily required to synthesize and evaluate the information they read. Therefore, the need to align reading instruction with these higher order thinking skills is in demand.

\subsection{Problem-solving Strategies}

These strategies are those used by the readers when directly working with the texts through steps and actions. The trend of problem-solving strategies as perceived by the students seems to be strongly preferred by the students over the other types of strategies. According to Alrabah and $\mathrm{Wu}$ (2019), one of the most consistent findings on research on metacognitive strategies is that problem-solving strategies have been preferred by learners from a variety of native languages. Additionally, these findings suggest similar findings to those of Miller (2017) and Dumlaio, et al (2019) in which the respondents tend mostly to perceive problem-solving strategies as the 
mostly frequently used strategies in comparison with global and support strategies. Non-native readers also tend to mostly use problem-solving strategies as these are vital for reading comprehension (Sheorey and Mokhtari, 2001). Relatively high frequencies of these strategies are marked by high frequencies of 'always' option. The highest perceived use of strategies is shown by P1, P4, and P7. Reading slowly and carefully to ensure understanding (P1) indicates deep reading and maintaining quest for understanding the text. Both P4 and P7 are also among the most critical strategies EFL learners need in order to tackle difficult texts in which more complex cognitive processes take place and require more time. In fact, reading strategies can be attributed to problem-solving strategies used to deal with the text (Mekhlafi, 2017). The report on these highly used problem-solving strategies is probably due to English status as a foreign language which upscales the complexity of the text that requires students to process information longer and more carefully.

\subsection{Support Strategies}

Support strategies are ways intended to aid readers in reading comprehension. The means from the results of the questionnaire show relatively similar choices among the students. As seen in Table 4, the highest perceived use strategy is marking with underline or circle the information for better comprehension and short-term memory. The use of marks to key ideas in the text is intended for highlighting. Hedgcock and Ferris (2009) additionally point out that highlighting is a helpful skill for intensive reading especially for checking comprehension while reading and reviewing after reading. At this point, skilled readers do know what to highlight. Skilled readers also think about the topic, go back and forth in the text and check their understanding as they read (Ko, 2019). The second highest use of the strategy is using reference material such as a dictionary. According to Hedgcock and Ferris (2009), consulting to either monolingual or bilingual dictionary can foster readers' autonomy, vocabulary mastery as well as better comprehension. Apart from these, two strategies, S8 and S9, highlight the role of L1. Proficient readers in L1 might possess good reading strategies in their L1 reading, yet encounter difficulties when coming across L2 or foreign language reading. Therefore, translating or thinking in native language might be helpful to some extent in reading comprehension.

\section{Conclusion}

Although the findings show moderate to high use of sub strategies of metacognitive strategies, it is imperative for students to be able to have knowledge on these strategies. Thuy (2020) expounds that skilled readers possess knowledge about cognition entailing declarative, procedural, and conditional knowledge. Declarative knowledge refers to knowing about what the reading strategies are. Possessing this knowledge is prerequisite for the readers to enable them to effectively use the strategies. Procedural knowledge furthermore means knowledge on how to use and process the strategies for effective reading. In addition, conditional knowledge refers to knowledge about when and why to use the strategies in appropriate manner. Finally, it can be concluded that most of the students that responded to the questionnaire are skilled readers and 
make use of a variety of strategies for textual comprehension. There is also a demand to carry out pedagogical intervention in order to explicitly teach these strategies in reading instruction through modelling and scaffolding. Snow (2002) justifies this view as meaning is non-existent in the text, rather is constructed therefore it is necessary to carry out instruction on how to use these strategies for better comprehension.

\section{References}

Ahmadi, Hairul, M.R., Ismail1, N. \& Abdullah, M.K.K. (2013). The Importance of Metacognitive Reading Strategy Awareness in Reading Comprehension. English Language Teaching, 6(10): 235-244. doi:10.5539/elt.v6n10p235

Al-Mekhlafi, A. M. (2018). EFL Learners Metacognitive Awareness of Reading Strategies. International Journal of Instruction, 11(2), 297-308. https://doi.org/10.12973/iji.2018.11220a

Alrabah, S. \& Wu, S. (2019). A descriptive analysis og the metacognitive strategies employed by EFL college students in Kuwait. International Journal of English Linguistics, 9(1): 2535. https://doi.org/10.5539/ijel.v9n1p25

Chamot, A. U., \& O'Malley, J. M. (1994). The CALLA handbook: Implementing the cognitive academic language learning approach. Reading, MA: Addison-Wesley.

Cogmen, S. \& Saracaloglu, A.S. (2009). Students' usage of reading strategies in the faculty of education. Procedia Social and Behavioral Sciences 1: 248-251

Dardjito, H. (2019). Students' Metacognitive Reading Awareness and Academic English Reading Comprehension in EFL Context. International Journal of Instruction, 12(4), 611624. https://doi.org/10.29333/iji.2019.12439a

Di Martino, V. \& La. Marca, A. (2019). Assessing metacomprehension and metacognitive strategies. IOSR Journal of Research Method in Education 9(2): 38-48

Dumlaio, R.P., Himmapan, K., Kueasnou, I. and Wanakprakobkul, J. (2019). Metacognitive awareness in reading English language text: A perspective from EFL undergraduate students in Thailand. The $2^{\text {nd }}$ International Conference on Applied Liberal Arts pp 87-95

Hamilton, J. (2018). Academic reading requirements for commencing HE students - A professional reflection on whether per reviewed journals are the right place to start. A Practice Report. Student Success, 9(2), 73-79. doi: 10.5204/ssj.v9i2.408

Harrison, C. (2004). Understanding reading. London: Sage Publication

Hassan, F. (2003). Metacognitive strategy awareness and reading comprehension. The English Teacher. 32: 16-33

Hedgcock, J.S, \& Ferris, D.R. (2009). Teaching readers of English: Students, texts, contexts. New York: Routledge 
Hermida, J. (2009). The importance of teaching academic reading skills in first-year university courses. The International Journal of Research and Review. Volume 3: 20-31

Miller, Gulhan, (2017). Metacognitive awareness and reading strategy use: Investigating the intermediate level ESL students' awareness of metacognitive reading strategies. Culminating Projects in English. 115. https://repository.stcloudstate.edu/engl_etds/115

Mokhtari, K., \& Reichard, C. A. (2002). Assessing students' metacognitive awareness of reading strategies. Journal of Educational Psychology, 94(2), 249-259.doi:10.1037//00220663.94.2.249

Mokhtari, K., \& Sheorey, R. (2002). Measuring ESL Students' Awareness of Reading Strategies. Journal of Developmental Education, 25(3), 2-10.

Mokhtari, Kouider, (2017). Raising students' metacognitive awareness of reading strategies helps improve their reading comprehension performance. Professional Development. Paper 72.

Sheikh, I, Soomro, K.A., \& Hussain, N. (2019). Metacognitive awareness of reading strategy, Reading practices and academic attainments of university students. Journal of Education and Educational Development 6(1): 126-137

Sheorey, R., and Mokhtari, K. (2001) Differences in the metacognitive awareness of reading strategies among native and non-native readers. System, vol. 29, pp. 431-449.

Snow, C.E. (2010). Reading comprehension: Reading for learning. International Encyclopedia of Education, 5: 413-418

Snow, C.E. (2002). Reading for understanding: toward a research and development program in reading comprehension. California: RAND

Yuksel, I. and Yuksel, I. (2012). Metacognitive awareness of reading strategies. Procedia Social and Behavioral Science, 31: 894-898 